\title{
The Development of a Representative Porcine Early- Onset Scoliosis Model With a Standalone Posterior Spinal Tether
}

Citation for published version (APA):

Bogie, R., Roth, A. K., Willems, P. C., Weegen, W., Arts, J. J., \& Van Rhijn, L. W. (2017). The

Development of a Representative Porcine Early-Onset Scoliosis Model With a Standalone Posterior

Spinal Tether. Spine Deformity, 5(1), 2-10. https://doi.org/10.1016/j.jspd.2016.09.002

Document status and date:

Published: 01/01/2017

DOI:

10.1016/j.jspd.2016.09.002

Document Version:

Publisher's PDF, also known as Version of record

\section{Document license:}

Taverne

Please check the document version of this publication:

- A submitted manuscript is the version of the article upon submission and before peer-review. There can be important differences between the submitted version and the official published version of record.

People interested in the research are advised to contact the author for the final version of the publication, or visit the DOI to the publisher's website.

- The final author version and the galley proof are versions of the publication after peer review.

- The final published version features the final layout of the paper including the volume, issue and page numbers.

Link to publication

\footnotetext{
General rights rights.

- You may freely distribute the URL identifying the publication in the public portal. please follow below link for the End User Agreement:

www.umlib.nl/taverne-license

Take down policy

If you believe that this document breaches copyright please contact us at:

repository@maastrichtuniversity.nl

providing details and we will investigate your claim.
}

Copyright and moral rights for the publications made accessible in the public portal are retained by the authors and/or other copyright owners and it is a condition of accessing publications that users recognise and abide by the legal requirements associated with these

- Users may download and print one copy of any publication from the public portal for the purpose of private study or research.

- You may not further distribute the material or use it for any profit-making activity or commercial gain

If the publication is distributed under the terms of Article $25 \mathrm{fa}$ of the Dutch Copyright Act, indicated by the "Taverne" license above, 


\section{Spine Deformity}

www.spine-deformity.org

\title{
Basic Science
}

\section{The Development of a Representative Porcine Early-Onset Scoliosis Model With a Standalone Posterior Spinal Tether}

\author{
R. Bogie, $\mathrm{MD}^{\mathrm{a}, \mathrm{b}, *}$, A.K. Roth, $\mathrm{MSc}^{\mathrm{a}}$, P.C. Willems, $\mathrm{MD}, \mathrm{PhD}^{\mathrm{a}}$, vd W. Weegen, $\mathrm{PhD}^{\mathrm{b}}$, \\ J.J. Arts, $\mathrm{PhD}^{\mathrm{a}}$, L.W. van Rhijn, MD, $\mathrm{PhD}^{\mathrm{a}}$ \\ ${ }^{a}$ Department of Orthopaedic Surgery, CAPHRI school for Public Health and Primary Care, Maastricht University Medical Centre, Maastricht, \\ the Netherlands \\ ${ }^{\mathrm{b}}$ Department of Orthopaedic Surgery, St. Anna Hospital, Geldrop, the Netherlands \\ Received 9 March 2016; revised 18 August 2016; accepted 4 September 2016
}

\begin{abstract}
Study Design: In vivo analysis in a porcine model.

Objectives: To develop a porcine experimental scoliosis model representative of early-onset scoliosis (EOS) with the use of a radiopaque ultra-high molecular weight polyethylene (UHMWPE) posterior spinal tether.

Summary of Background Data: Large animal experimental scoliosis models with substantial growth potential are needed to test new fusionless scoliosis correction techniques. Previously described scoliosis models involve rib procedures, which violate the thoracic cage and affect subsequent corrective procedures. Models omitting these rib procedures have experienced difficulties in producing persistent three-dimensional structural deformities representative of EOS.

Methods: Scoliosis was induced in 14 immature pigs using an asymmetric posterior radiopaque UHMWPE spinal tether fixated to an offset device at lumbar and thoracic levels. Radiographs were taken at 2-week intervals, and frontal and sagittal Cobb angles were measured. A tether release was performed at the 10-week follow-up, and the animals were observed for another 10 weeks.

Results: Four animals had complications (infections and/or screw breakout) and were excluded from the study. Eight animals developed progressive curves with a mean frontal Cobb angle of $62^{\circ}$. A thoracic lordosis $\left(34^{\circ}\right)$ and a thoracolumbar kyphosis $\left(22^{\circ}\right)$ formed. CT analysis, acquired prior to tether release, showed a mean vertebral rotation of $37^{\circ}$ at the apex with a mean vertebral wedge angle of $10^{\circ}$. After tether release, the frontal Cobb angles decreased to $46^{\circ}$ at the 20-week follow-up. Sagittal curvature was not substantially affected after tether release. Conclusions: We describe a large animal scoliosis model, which exhibits a substantial deformity in three planes without the use of rib procedures additional to a posterior spinal tether. The created deformities showed persistence after tether release. With the management of infection and enhancement of instrumentation stability, the creation of a valid model for testing new devices in fusionless scoliosis surgery seems feasible.
\end{abstract}

Level of Evidence: Level V.

(C) 2016 Scoliosis Research Society. All rights reserved.

Keywords: Early-onset scoliosis; Radiopaque UHMWPE tether; Scoliosis model; Wedging; Rotation

Author disclosures: RB (none); AKR (none); PCW (none); VDWW (none); JJA (none); LWVR (none).

This study was funded by the Dutch BioMedical Materials (BMM) program co-funded by the Dutch Ministry of Economic Affairs. This study is part of the BMM (BioMedical Materials program is 2010-10595) Spineguide research project $(\mathrm{P} 2.05)$. Dyneema Purity is a registered trademark of DSM.

The authors thank the employees of the animal facility of the Maastricht University Medical Centre for their assistance during this study, with special thanks to Ms S. Bout and Ms P. Dijkstra.

*Corresponding author. Department of Orthopaedic Surgery, Maastricht University Medical Centre, P.O. Box 5800, NL-6202 AZ Maastricht, the Netherlands. Tel.: +31-43-3875037; fax: +31-43-3874893.

E-mail address: robbogie@hotmail.com (R. Bogie).

\section{Introduction}

Within the last decades, it has become clear that fusionless surgical scoliosis correction techniques are essential for the treatment of early-onset scoliosis (EOS), but their merits and potential are also increasingly explored for the treatment of adolescent idiopathic scoliosis (AIS). For EOS patients, it is imperative to retain longitudinal spine growth, thereby maintaining volumetric thoracic cage growth and lung development [1]. Fusionless scoliosis correction devices for EOS patients may be classified into growth-guidance (Shilla and Luque trolley) or 
distraction-based techniques (growing rods, vertical expandable prosthetic titanium rib) [2]. For AIS patients, compression-based anterior devices are used to modulate vertebral growth by utilizing the Hueter-Volkmann principle [3] to slow or halt growth on the convex side of the deformity, thereby attaining gradual curve correction. Examples of such compression-based modulation are the use of vertebral body staples and an anterior spinal tether [2].

The most generic method for the preclinical evaluation of fusionless scoliosis correction devices is using a two-step approach: A structural, idiopathic-like scoliosis is created in a first procedure and later corrected using the proposed scoliosis correction device in a second procedure. Posterior spinal tethering is the preferred index procedure [4], as it produces significant, progressing deformities that most closely approximate the three-dimensional (3D) nature of the deformity as seen in idiopathic scoliosis (progressive coronal curvature, loss of thoracic kyphosis, and axial vertebral rotation) [5-7].

We have previously reviewed large animal models in fusionless scoliosis correction research [8]. The similarity between human and porcine spinal anatomy in addition to the fast, large growth rate makes pigs commonly used animals for experimental scoliosis models. The main differences between models described by different authors are age at index procedure, length of follow-up period, pretensioning of the tether, and whether rib procedures (rib tethering with or without rib resection) additional to the spinal tether were performed. Rib procedures may lead to high postoperative morbidity and may cause spontaneous rib fusion with a very stiff curve as a result [9]. These irreversible thoracic changes will affect subsequent testing procedures. Odent et al. $[10,11]$ have demonstrated that rib tethering may be omitted when sufficient spinal tether offset is used. However, their described model exhibited substantial loss of deformity, loss of approximately $45 \%$ of the curve magnitude in the frontal plane, after tether release.

The purpose of this study was to create an early-onset scoliosis model, without additional rib procedures, in which all 3D scoliosis-like structural changes occur and persist after tether release. A posterior technique with a radiopaque flexible ultra-high molecular weight polyethylene (UHMWPE) spinal tether with an offset device was used to create a progressive lordoscoliotic curve. This model should ultimately allow for preclinical testing of fusionless scoliosis correction techniques in a growing animal.

\section{Material and Methods}

\section{Surgical procedure}

All animal procedures were approved by the Animal Ethical Committee of the Maastricht University Medical Center (approval no.: DEC 2011-005). A total of 16 immature landrace pigs (female, 8 weeks old, weight range $10-13 \mathrm{~kg}$ ) were included in this study. Each operation was performed under strict, sterile conditions. Antibiotics (amoxicillin/clavulanic acid $1.2 \mathrm{~g}$ ) were administered intravenously 1 hour before incision and 6 hours postoperatively. After 7 days of acclimatization at the institutional animal facility, the animals were sedated by intravenous administration of thiopental $(10-15 \mathrm{mg} / \mathrm{kg})$, followed by endotracheal intubation and general anesthesia using $1 \%$ to $2 \%$ isoflurane. Pain medication was administered and adjusted if needed during surgery (sufentanil $10-30 \mu \mathrm{g} / \mathrm{kg}$ per hour intravenously). Electrocardiogram registration, ventilation curves, temperature, oxygen saturation level, and heart rate were continuously monitored. With the animal in prone position, two small midline incisions were made at thoracic and lumbar levels under fluoroscopic control. The transverse processes and the facet joints were minimally exposed unilaterally on the left side by partially detaching the erector spinae using electrocautery.

\section{Instrumentation technique and material specification}

In a pilot study involving two animals, polyaxial pedicle screws $(4.5 \mathrm{~mm}$ diameter, $22-26 \mathrm{~mm}$ length; Vertex, Medtronic) were placed unilaterally at T6-T7 and L1-L2 under fluoroscopic guidance. Two custom-made offset devices ( $28 \mathrm{~mm}$ offset from pedicle screws) were fixed using a 3.2-mm titanium rod in between each set of adjacent pedicle screws (Fig. 1). A 4-mm-wide flat wire woven from ultra-high molecular weight polyethylene (UHMWPE) Dyneema Purity ${ }^{\circledR}$ Radiopaque fibers (DSM
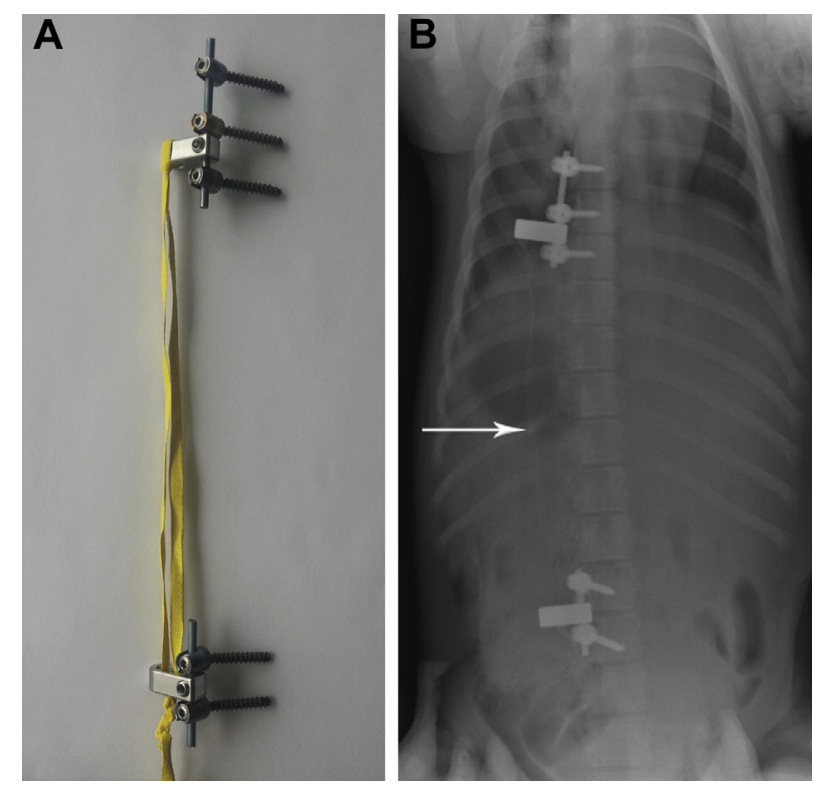

Fig. 1. (A) Offset devices with rods, pedicle screws and the radiopaque ultra-high molecular weight polyethylene (UHMWPE) double loop tether. (B) Offset device implanted in the porcine spine. The radiopaque tether (arrow) is attached to the offset devices without any tension. 
Biomedical B.V., Geleen, the Netherlands) was used as a posterior tether. Bismuth oxide $\left(\mathrm{Bi}_{2} \mathrm{O}_{3}\right)$ particles are blended into each individual fiber for radiopacity [12]. The wire was folded in half and the two ends were passed through the cranial offset device and through the loop created in the wire, thereby securing the cranial end of the tether. The caudal end was secured using multiple square knots. In these initial two animals, the UHMWPE tether was placed under tension before fixation. This created a Cobb angle of approximately $20^{\circ}$. After 4 weeks, screw breakout was observed at both caudal and cranial levels with loss of deformity. The large offset in combination with pretensioning of the tether was assumed to be the reason for this early failure. For this reason, in the definitive series of animals $(n=14)$ the construct was altered slightly. First the thoracic offset device was secured using three instead of two thoracic pedicle screws (T5-T7), and the lumbar instrumentation was reinforced with a UHMWPE sublaminar wire [13]. Furthermore, no pretension was applied to the tether and the offset was reduced to $20 \mathrm{~mm}$. In the first four animals, proximal fixation was located at levels T5-T7 with caudal fixation on L1-L2. After experiencing problems reaching the deep cranial thoracic vertebra because of thick musculature in these first four procedures, the proximal fixation site was moved to levels $\mathrm{T} 7-\mathrm{T} 9$ and distal fixation site to $\mathrm{L} 2-\mathrm{L} 3$.

\section{Observation, radiology, and tether release}

The wound was ultimately closed in layers. Postoperative pain management (buprenorphine $0.05 \mathrm{mg} / \mathrm{kg}$, carprofen $2-4 \mathrm{mg} / \mathrm{kg}$ intramuscularly) was provided until the animals had returned to activities ad libitum. Antibiotic treatment was administered intramuscularly 6 hours after surgery. Initially, no postoperative wound dressing was applied. However, as three of the first four animals developed postoperative wound infections, the wound was dressed using an iodide film, which was kept in place for 3 days postoperatively. No more wound infections occurred in the subsequent animals.

One animal with a profound infection was euthanized because of instrumentation failure and observed animal discomfort. In the other animals with wound infections, the infection was controlled with the administration of antibiotics (amoxicillin/clavulanic acid $1.2 \mathrm{~g}$ ) for several days and wound lavage without loss of the curvature.

Plain full spine radiographs were taken directly postoperatively and subsequently at 2 -week intervals under light tiletamine-zolazepam $(8 \mathrm{mg} / \mathrm{kg})$ sedation. Routine supine dorsoventral and lateral radiographs were acquired to assess curve progression. Frontal and sagittal Cobb angles were measured at each radiologic assessment. Radiographs were also analyzed for positioning and possible pullout or breakage of the instrumentation.

\section{Tether release and computed tomographic analysis}

At 10-week follow-up and upon reaching a frontal Cobb angle of minimally $40^{\circ}$, a tether release was performed in eight animals. The radiopaque tether was localized under fluoroscopy and cut through a minimal stab incision at the caudal end. Animals were followed for another 10 weeks with radiographs every 2 weeks, and euthanization was performed using pentobarbital overdose $(200 \mathrm{mg} / \mathrm{kg})$. After sacrifice, the spines were harvested.

Computed tomographic (CT) scans were acquired before tether release at the 10-week follow-up under general anesthesia (Somatom Definition Flash; Siemens, Erlangen, Germany). Three-dimensional reconstructions of each spine were obtained to assess vertebral rotation, rib hump, and apical vertebra wedging. Rib hump elevation located at the convex side was considered a positive result for the model. Vertebral rotation was measured relative to the anterior midline of the body $[14,15]$. Rotation and rib hump were assessed by analyzing a transversal CT slice at the level of the apex vertebra using the Synedra View program (Synedra, Innsbruck, Austria). The position of the apical vertebra was determined in three planes. Apical vertebral wedging was measured from the reconstructed coronal CT images. Convex and concave heights for each apical vertebra were also determined.

\section{Results}

Of the 14 animals included within the definitive surgical protocol, one animal died as a result of respiratory distress after extubation. Autopsy did not reveal any other cause of death. No neurologic complications occurred during any of the surgeries. Mean weight gain was approximately $5 \mathrm{~kg} /$ week. Eight animals developed a structural complex 3D scoliotic curvature with a chest wall deformity and a positive rib hump elevation. In this group, the mean Cobb angle at the 10 -week follow-up was $62^{\circ}$ (range $43^{\circ}-72^{\circ}$ ) in the frontal plane (Fig. 2). In the sagittal plane, a thoracolumbar kyphosis developed between the anchor sites $\left(22^{\circ}\right.$, range $\left.7^{\circ}-44^{\circ}\right)$, and a thoracic lordosis formed at the anchor levels $\left(35^{\circ}\right.$, range $\left.21^{\circ}-53^{\circ}\right)$, presumably as a result of continued anterior growth (crankshafting) (Fig. 3). In five animals, a long-segment curvature (11-12 vertebrae in the curvature) with large Cobb angles (mean $68.3^{\circ}$ ) developed. In three animals, a shorter (5-6 vertebrae in the curvature) thoracic curve (mean $51.9^{\circ}$ ) developed probably because of an epiphysiolysis or fracture of one vertebra, which was observed in both anchor location groups (T5-T4-T3/L1-L2 and T7-T6-T5/L2-L3). In three animals, screw breakout or slippage of the knot securing the tether was observed, resulting in loss of the curvature, and therefore these animals were sacrificed. In two animals, the cause of this failure was not determined. The other case had developed a postoperative infection 

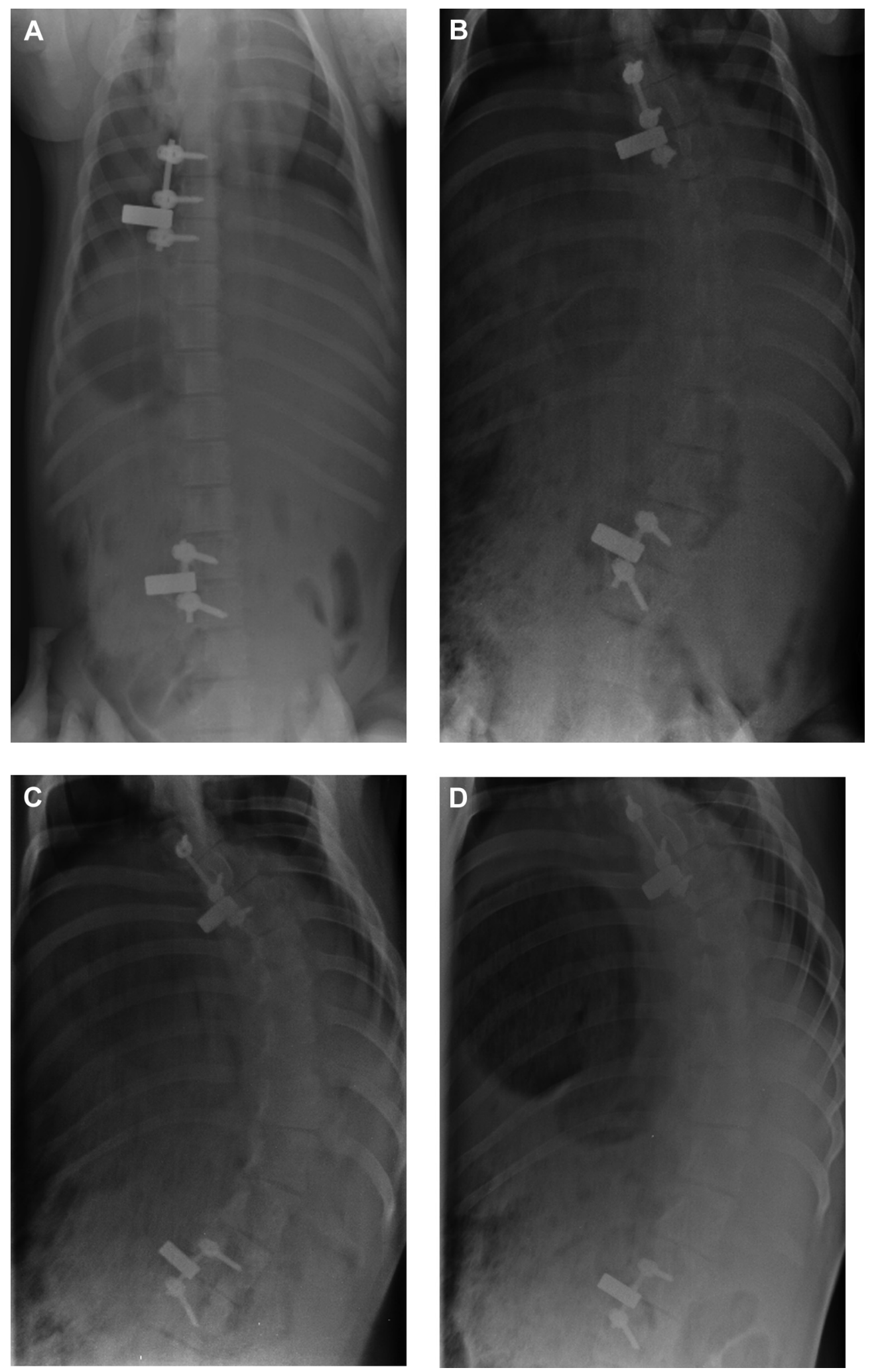

Fig. 2. (A) Instrumentation with straight spine direct postoperatively. (B) Four-week follow-up with the development of a C-type curvature with thoracic asymmetry. (C) Ten-week follow-up before tether release. (D) Twenty-week follow-up with slight loss of curvature 10 weeks after tether release. 

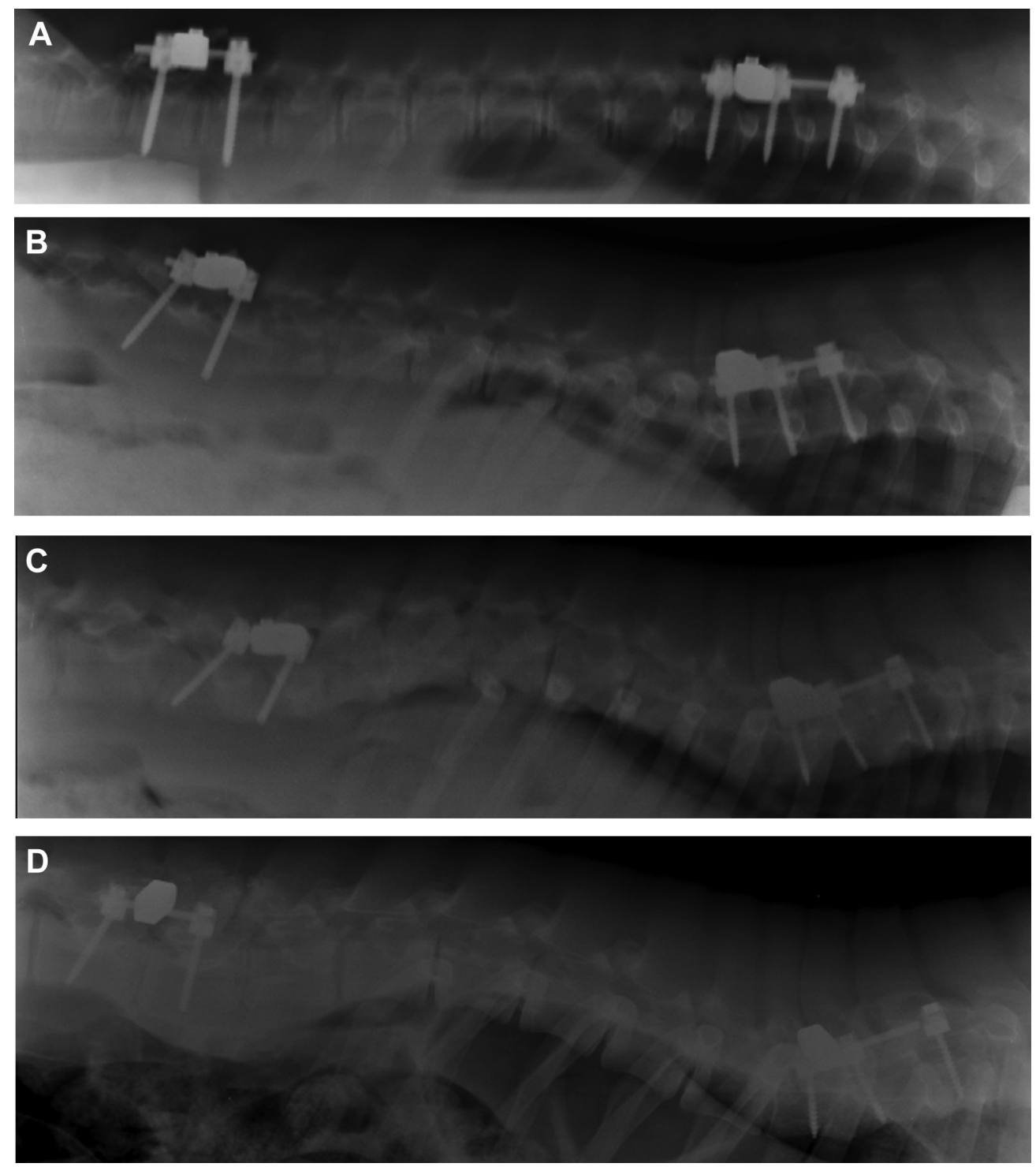

Fig. 3. Lateral radiographs. (A) Instrumentation with nearly straight spine postoperatively. (B) Four-week follow-up with the development of a small thoracic lordosis. (C) Ten-week follow-up before tether release with presence of a thoracolumbar kyphosis and thoracic lordosis. (D) Twenty-week follow-up with unchanged curvature 10 weeks after tether release.

with the observation of radiolucency around the screws. Loosening of the screws eventually resulted in failure of instrumentation. The final two animals developed curves with Cobb angles of $31^{\circ}$ and $34^{\circ}$, which did not progress any further because of unknown reasons. These animals were also subsequently sacrificed. CT scanning and subsequent tether release was performed in the eight animals that developed progressive structural scoliosis. These animals were followed for an additional 10-week time period after tether release (Fig. 4). CT imaging revealed structural characteristics of the deformity, with most wedging and axial rotation occurring at the apex of the curvature (Fig. 5). The mean apical vertebral rotation was $37.3^{\circ}$ (range $25^{\circ}-54^{\circ}$ ), while substantial apical wedging also occurred: convex height minus concave height measured a mean of $4.2 \mathrm{~mm}$, which resulted in a mean vertebral wedge angle of $10.4^{\circ}$ (range $5.7^{\circ}-17.2^{\circ}$ ) (Fig. 6).

After tether release, the frontal Cobb angles immediately decreased from $62^{\circ}$ to $56^{\circ}$ and showed a further decrease at 10 weeks' additional follow-up to $46.7^{\circ}$ (Fig. 7, Table 1). In two animals, there was loss of curvature within the midsegments at 20 weeks' follow-up. Lateral tilting of the cranial and caudal segments, however, still resulted in a curvature with persistent thoracic asymmetry. Sagittal profiles did not show substantial changes after tether release (Table 2). 


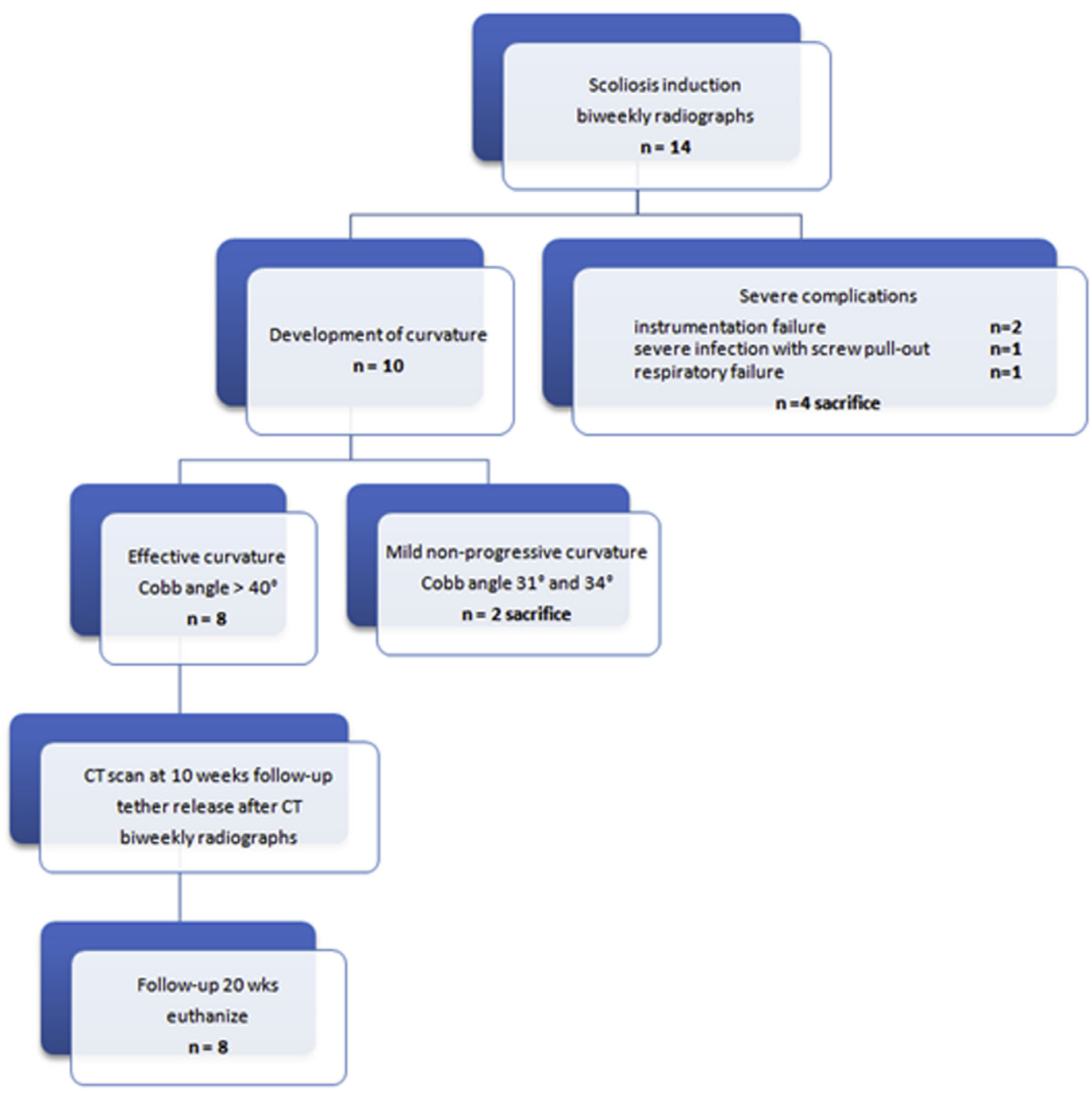

Fig. 4. Flowchart of experimental group.
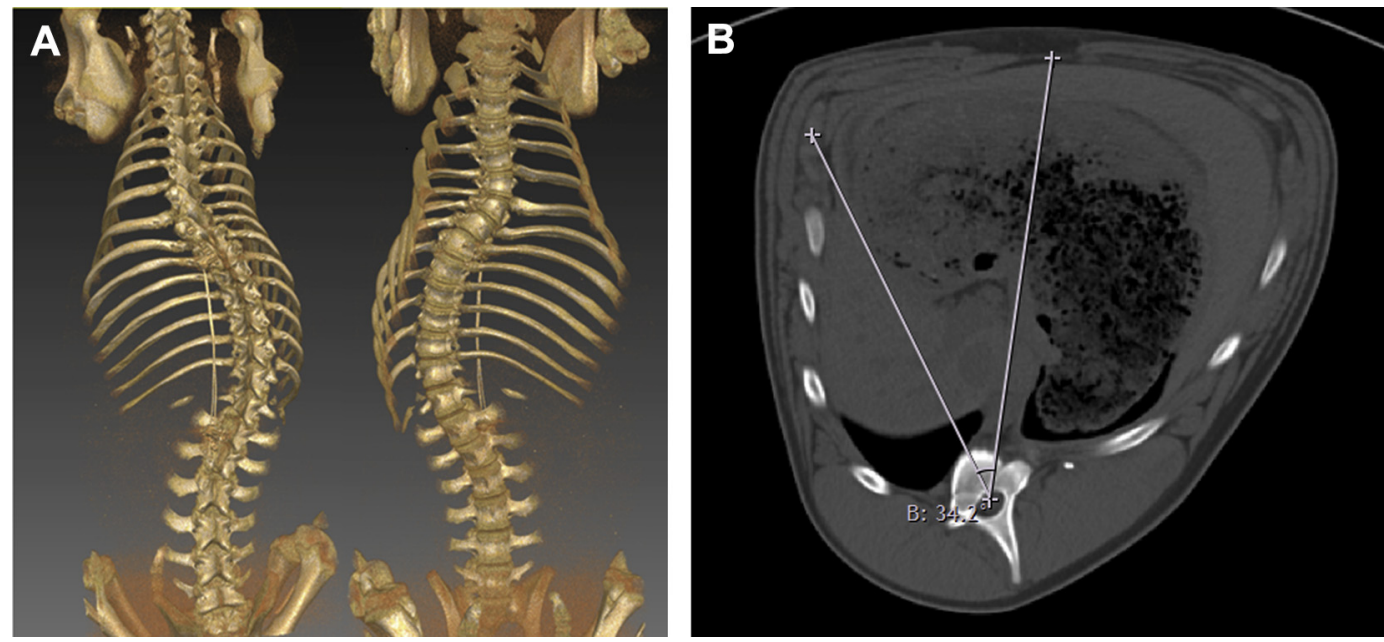

Fig. 5. (A) Frontal (right) and posterior (left) view of a three-dimensional computed tomographic (CT) reconstruction of the lordoscoliotic deformity at the 10-week follow-up before release of the tether. Sagittal reconstruction clearly showing the thoracic asymmetry. (B) Axial CT slice showing how rotation was measured at the level of the apical vertebra by measuring the angle between the anterior midline and the line perpendicular to the transverse processes. 


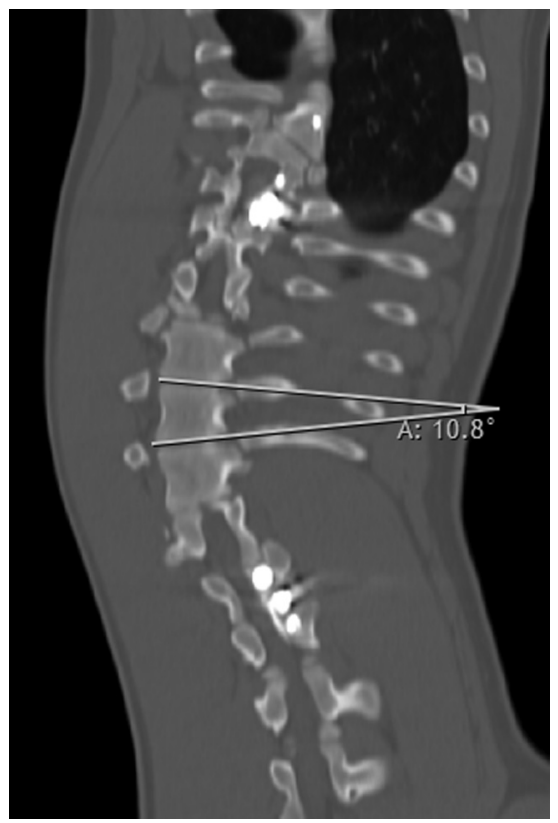

Cobb angle frontal curve (degrees)

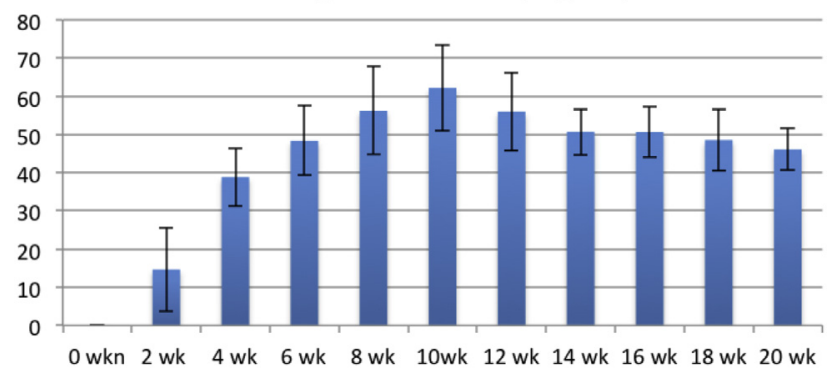

Fig. 7. Evolution of scoliosis after placement of the tether. At 10-week follow-up, the tether release is performed.

Fig. 6. Coronal reconstructed image showing the wedging of the apical vertebrae.

Table 1

Evolution of the Cobb angles before and after tether release and at 10 weeks post tether release.

\begin{tabular}{|c|c|c|c|c|c|c|c|c|c|c|}
\hline \multirow[t]{3}{*}{ Animal } & \multirow[t]{3}{*}{ Instrumentation level } & \multicolumn{9}{|c|}{ Cobb angle } \\
\hline & & \multicolumn{3}{|c|}{ Precut tether $10 \mathrm{wks}$} & \multicolumn{3}{|c|}{ Post tether release } & \multicolumn{3}{|c|}{ End follow-up 20 wks } \\
\hline & & Frontal & \multicolumn{2}{|l|}{ Sagittal } & Frontal & \multicolumn{2}{|l|}{ Sagittal } & Frontal & \multicolumn{2}{|l|}{ Sagittal } \\
\hline 1 & $\mathrm{~L} 1-\mathrm{L} 2 / \mathrm{T} 5-\mathrm{T} 4-\mathrm{T} 3$ & 72.4 & 44.1 & 19.8 & 58.2 & 39.1 & 16.6 & 44.5 & 32 & 12 \\
\hline 2 & $\mathrm{Ll}-\mathrm{L} 2 / \mathrm{T} 5-\mathrm{T} 4-\mathrm{T} 3$ & 61.7 & 44 & 20 & 51 & 38.6 & 19.6 & 39,4 & 32.7 & 13.6 \\
\hline 3 & $\mathrm{~L} 1-\mathrm{L} 2 / \mathrm{T} 5-\mathrm{T} 4-\mathrm{T} 3$ & 43.3 & 21.4 & 6.8 & 38.6 & 28.5 & 6.8 & 40.7 & 30 & 4.4 \\
\hline 6 & $\mathrm{~L} 2-\mathrm{L} 3 / \mathrm{T} 7-\mathrm{T} 6-\mathrm{T} 5$ & 70.7 & 30.2 & 17 & 65.2 & 28.1 & 14.6 & 52.6 & 40.7 & 4.5 \\
\hline 7 & $\mathrm{~L} 2-\mathrm{L} 3 / \mathrm{T} 7-\mathrm{T} 6-\mathrm{T} 5$ & 60.9 & 20.1 & 30 & 58.8 & 20.4 & 23.2 & 43.2 & 29.8 & 20 \\
\hline 8 & $\mathrm{~L} 2-\mathrm{L} 3 / \mathrm{T} 7-\mathrm{T} 6-\mathrm{T} 5$ & 49.7 & 53.3 & 44 & 48.2 & 35.8 & 31.2 & 51.8 & 36.6 & 33.5 \\
\hline Mean & & 62.1 & 34.3 & 21.8 & 56.0 & 34.5 & 18.4 & 46.7 & 35.9 & 15 \\
\hline
\end{tabular}

${ }^{\mathrm{a}}$ Extra pedicle screw insertion because of minimal screw support.

${ }^{\mathrm{b}}$ Quality of radiographs not suitable for adequate sagittal measurements.

Table 2

Spinal parameters with Cobb angle, apical vertebrae rotation and wedging of the different specimen at 10-week follow-up before tether release.

\begin{tabular}{|c|c|c|c|c|c|c|}
\hline Animal & Cobb frontal $\left({ }^{\circ}\right)$ & $\begin{array}{l}\text { Apical vertebral } \\
\text { rotation }\left({ }^{\circ}\right)\end{array}$ & $\begin{array}{l}\text { No. of vertebrae } \\
\text { in curve }\end{array}$ & $\begin{array}{l}\text { Vertebral } \\
\text { wedging }\left({ }^{\circ}\right)\end{array}$ & Height convex (mm) & $\begin{array}{l}\text { Height } \\
\text { concave }(\mathrm{mm})\end{array}$ \\
\hline 1 & 72.4 & 44.4 & 11 & 5.7 & 25.9 & 24.4 \\
\hline 2 & 61.7 & 36.2 & 11 & 6.8 & 25.1 & 22.1 \\
\hline 4 & 62.8 & 54.4 & 6 & 9.7 & 28.2 & 23.4 \\
\hline 5 & 75.6 & 36.9 & 12 & 16.1 & 26.6 & 19.5 \\
\hline 6 & 70.7 & 43.1 & 11 & 8.5 & 28.8 & 24.7 \\
\hline Mean & 62.1 & 37.3 & 9.1 & 10.4 & 27 & 22.8 \\
\hline
\end{tabular}




\section{Discussion}

Numerous attempts have been made to create reproducible large animal scoliosis models for preclinical evaluation of fusionless scoliosis correction techniques [4,8,10,14,16-19]. A representative experimental earlyonset scoliosis model should exhibit the following features: structural, persistent frontal and sagittal curvatures with sufficient rotation and wedging at the apex of the curvature, and adequate growth potential remaining to perform subsequent correction procedures [8].

Despite experiencing several technical problems in our study, we were able to create a scoliosis-like deformity, progressive while the tether was in situ in 8 of 14 animals without the use of rib tethering procedures. Magnitudes and $3 \mathrm{D}$ characteristics of the attained curves showed idiopathiclike features, with a mean Cobb angle of $62^{\circ}$ and a mean vertebral rotation of $37^{\circ}$ at the apex vertebra. The sagittal profile was not predominantly lordotic, and curves were therefore not idiopathic-like in that sense. The three shorter thoracic curves with rigid segments, formed as a result of vertebra fracture or epiphysiolysis, are less idiopathic-like and perhaps more similar to a congenital scoliosis. Such curves would be of limited usefulness for the assessment of fusionless scoliosis correction techniques. The low yield and the low consistency of our model remains a concerning issue. Four animals were sacrificed as a result of instrument failure or infection. Infections were prevented after changing the surgical preparation protocol. Despite not applying tether pretension, screw pullout still occurred in three animals. In one case, osteolysis surrounding the screws caused by infection probably resulted in this loss of fixation at the bone-screw interface.

After our pilot study in which pretension was applied to the tether and instrumentation failure occurred within 2 weeks postoperatively, we reasoned that pretensioning of the tether causing an immediate scoliosis should not be performed. Schwab et al., however, demonstrated that the larger the initial curve (up to approximately $25^{\circ}$ ) as induced by applying tension at surgery, the higher the rate of progression observed [11]. In their study, sublaminar cables were used to reinforce the screws and instrumentation was probably partially protected by an ipsilateral rib tether. Zheng et al. have also described a porcine scoliosis model with the use of a posterior tether in combination with an ipsilateral rib tether [20]. By pretensioning the posterior tether, a curvature of $29^{\circ}$ was initiated and progressed to $65^{\circ}$ at an 8 -week tethering period. Apparently, the rib tether aids in early induction of the deformity, reduces load on the spinal tether anchors, and helps avoid screw pullout. Our objective was to develop a persistent spinal deformity representative of EOS with the use of a radiopaque UHMWPE posterior tether and without additional rib procedures. We believe a rib tether violates the chest wall structures and causes irreversible ribcage deformity with the formation of ectopic bone and stiff curves as a result.
Subsequent corrective surgery may therefore be more difficult to perform. By omitting rib procedures, we aimed to create less rigid curves, especially around the apex, which subsequently resulted in nonprogressive curves after tether release. Odent et al. have shown earlier that rib procedures can be omitted [10]. However, release of the tether after 2 months led to a regression of the deformity by $45 \%$ in their study. In our study, the mean frontal Cobb angle decreased from $62.1^{\circ}$ to $46.7^{\circ}$ over a 10 -week period after tether release. Despite the decline of $25 \%$, a substantial deformity ultimately remains, which is close to the magnitude that would be considered for surgery. Before tether release, the apical vertebrae showed a mean wedge angle of $10^{\circ}$. The emergence of vertebral wedging is necessary for the persistence of scoliotic deformity after tether release. Similarly, in the human spine, apical vertebral wedging is an essential factor in the progression of idiopathic scoliosis according to the Hueter-Volkmann principle [16]. Regression of the deformity can be seen as evidence of a flexible curve, which is a crucial prerequisite for applying growth modulation techniques. The omission of the rib tether exhibited two downsides in a porcine model: the incapability of applying pretension to the tether, and slight curve regression after tether release.

Selection of animal species with anatomy similar to humans' and timing of the procedures are vital factors for creating a successful scoliosis model with sufficiently large Cobb angles [8]. Braun was the first to produce progressive lordoscoliotic deformities in a goat model. However, large pathologic curves were obtained [16,17]. In addition to the pyramidal shape of the thorax, the relatively small size of the goat's vertebra as compared to the human vertebra makes the goat model less suitable for implant testing [21]. The porcine spine is most similar to the human spine in terms of vertebral body height and has the largest growth potential compared to other large animals, with a maximum growth velocity at 3-4 months of age [8]. We opted for pigs, reasoning that the large growth potential is required when no pretension is applied to the spinal tether. We performed the initial procedure at 8 weeks of age and a mean weight of $12 \mathrm{~kg}$. This is well before the growth velocity peak, leaving enough residual growth to evaluate the deformity after tether release (and perform a corrective procedure in the future). However, we experienced some handling problems with the animals, who reached a weight of approximately $50 \mathrm{~kg}$ at the time of tether removal and approximately $100 \mathrm{~kg}$ at 6 months of age (sacrifice). Other studies describing experimental scoliosis models report different rates of weight increase in pigs, and different rates of growth of the porcine spine, probably the result of discrepancy between porcine races $[10,11,20]$. The size of our animals during the possible implant test phase (between 50 and $100 \mathrm{~kg}$ ) is not representative of children under the age of 10 but allows for conceptual feasibility assessment of fusionless scoliosis correction techniques. The described low yield due to screw pullout and low consistency 
(epiphysiolysis) are also probably related to the rapid porcine growth phase. The use of mini-pigs or species with a slower growth rate such as sheep or goats may help avoid these problems [10,22]. Mini-pigs show a constant growth velocity but lack a growth spurt and will need longer observational periods [8].

Different types of tether materials have been used, and flexible tethers are preferred over a rigid tether in order to maintain spinal mobility and allow for growth modulation in different planes (lordoscoliosis) [10,14,20]. Nonmetal flexible tethers are also used although visualization of the integrity of the tether during follow-up is not possible. The use of a flexible, radiopaque UHMWPE tether [13] facilitated percutaneous tether release with a minimally invasive stab incision under fluoroscopic control. The tensioning and potential loosening of the radiopaque tether could easily be monitored during the postoperative radiologic evaluation, with minimal animal discomfort as a result of leaving the tether in place.

It is evident that measures should be taken to minimize the occurrence of wound infections, not only to decrease the incidence of instrumentation failure but also to decrease overall morbidity. Further limitations of our study include the lack of CT analysis at the 20-week follow-up. Therefore, we were not able to compare rotational deformity between different time points. Although we encountered several problems, we were able to create the foundation for a large animal scoliosis model, which exhibits a substantial 3D deformity without the use of rib procedures additional to a posterior spinal tether. The resulting deformities were not progressive but showed persistence after tether release. The high complication rate remains a concern and poses questions regarding the feasibility of subsequent corrective operative procedures. We conclude that despite extensive research and incorporating previous recommendations from other models, the development of a reproducible experimental scoliosis large animal model without severe complications remains challenging. We would like to emphasize that the current work requires further work and validation before adoption, preferably in an animal model with a slower growth rate, to improve the yield and consistency.

\section{References}

[1] Thompson GH, Lenke LG, Akbarnia BA, et al. Early onset scoliosis: future directions. J Bone Joint Surg Am 2007;89(suppl 1):163-6.

[2] Gomez JA, Lee JK, Kim PD, et al. "Growth friendly" spine surgery: management options for the young child with scoliosis. J Am Acad Orthop Surg 2011;19:722-7.

[3] Schmid EC, Aubin CE, Moreau A, et al. A novel fusionless vertebral physeal device inducing spinal growth modulation for the correction of spinal deformities. Eur Spine J 2008;17: 1329-35.

[4] Braun JT, Akyuz E, Ogilvie JW. The use of animal models in fusionless scoliosis investigations. Spine 2005;30:S35-45.

[5] Graf H, Hecquet J, Dubousset J. Three-dimensional approach to spinal deformities. Application to the study of the prognosis of pediatric scoliosis [in French]. Revue de chirurgie orthopedique et reparatrice de l'appareil moteur 1983;69:407-16.

[6] Dubousset J. Idiopathic scoliosis. Definition-pathology-classificationetiology [in French]. Bulletin de l'Academie nationale de medicine 1999;183:699-704.

[7] Dubousset J. Scoliosis and its pathophysiology: do we understand it? Spine 2001;26:1001.

[8] Roth AK, Bogie R, Jacobs E, et al. Large animal models in fusionless scoliosis correction research: a literature review. Spine J 2013;13: 675-88.

[9] Zhang YG, Zheng GQ, Zhang XS, et al. Scoliosis model created by pedicle screw tethering in immature goats: the feasibility, reliability, and complications. Spine 2009;34:2305-10.

[10] Odent T, Cachon T, Peultier B, et al. Porcine model of early onset scoliosis based on animal growth created with posterior miniinvasive spinal offset tethering: a preliminary report. Eur Spine J 2011;20:1869-76.

[11] Schwab F, Patel A, Lafage V, et al. A porcine model for progressive thoracic scoliosis. Spine 2009;34:E397-404.

[12] Ceelen K, Vaz C, Bremer L, et al. Development of a high-strength, biocompatible, radiopaque UHMWPE fiber. 24th European conference on biomaterials. Dublin, Ireland 2011.

[13] Bogie R, Roth A, Faber S, et al. Novel radiopaque UHMWPE sublaminar wires in a growth-guidance system for the treatment of early onset scoliosis: feasibility in a large Animal Study. Spine 2014;39: E1503-9.

[14] Burke JG, Vettorato E, Schoffmann G, et al. Creation of an ovine model of progressive structural lordo-scoliosis using a unilateral laminar tether. Eur Spine J 2015;24:1382-90.

[15] Lam GC, Hill DL, Le LH, et al. Vertebral rotation measurement: a summary and comparison of common radiographic and CT methods. Scoliosis 2008;3:16.

[16] Braun JT, Ogilvie JW, Akyuz E, et al. Experimental scoliosis in an immature goat model: a method that creates idiopathic-type deformity with minimal violation of the spinal elements along the curve. Spine 2003;28:2198-203.

[17] Braun JT, Ogilvie JW, Akyuz E, et al. Creation of an experimental idiopathic-type scoliosis in an immature goat model using a flexible posterior asymmetric tether. Spine 2006;31:1410-4.

[18] Moal B, Schwab F, Demakakos J, et al. The impact of a corrective tether on a scoliosis porcine model: a detailed 3D analysis with a 20 weeks follow-up. Eur Spine J 2013;22:1800-9.

[19] Ouellet J, Odent T. Animal models for scoliosis research: state of the art, current concepts and future perspective applications. Eur Spine J 2013;22(suppl 2):S81-95.

[20] Zheng X, Sun X, Qiu Y, et al. A porcine early-onset scoliosis model created using a posterior mini-invasive method: a pilot study. J Spinal Disord Tech 2014;27:E294-300.

[21] Braun JT, Akyuz E, Udall H, et al. Three-dimensional analysis of 2 fusionless scoliosis treatments: a flexible ligament tether versus a rigid-shape memory alloy staple. Spine 2006;31:262-8.

[22] Newton PO, Upasani VV, Farnsworth CL, et al. Spinal growth modulation with use of a tether in an immature porcine model. J Bone Joint Surg Am 2008;90:2695-706. 